\title{
E-Learning as A Proper Solution in Times of Emergency, Pandemic, and Uncertainty Against the Current Traditional Mode of Learning in Nigeria
}

\author{
Muzambilu Saminu ${ }^{1}$, Ibrahim Abubakar Sadiq ${ }^{2}$, Ali Idris ${ }^{3}$ \\ ${ }^{1}$ Department of Physics Mewar University, Chittorgarh Rajasthan India. \\ ${ }^{2}$ Department of Mathematics and Statistics, Mewar University, Chittorgarh, Rajasthan, India. \\ ${ }^{2}$ Department of Statistics, Ahmadu Bello University, Zaria, Nigeria. \\ ${ }^{3}$ Department of Science and Technology Education, Bayero Universty, Kano.
}

\begin{abstract}
The study elicits student's views on E-learning and their perceptions in the system of education currently been the practice in the country. The study adopts a questionnaire method of data collection generated using Google form and distributed via social media handles. Descriptive statistical analysis was carried out on the data generated. The findings show that students prefer E-learning to the traditional mode of teaching in the area covered by the study. The results of this study can be utilized by the government, private school proprietors and all other stakeholders in Nigeria's education sector to brings some more modifications and desirable changes to overcomes problems of schooling during the pandemic, emergency, and uncertainty.
\end{abstract}

Keywords: Education, E-learning, Nigeria, Statistics, Pandemic, social media.

\section{INTRODUCTION}

Nigeria is the most populated country in sub-Saharan Africa, the present population of the country stand at 205836204 as of $13^{\text {th }}$ June 2020, from the Worldometer of the up-to-date United Nations data. The total landmass of the country is $910770 \mathrm{Km}^{2}$ [1]. Education in Nigeria is administered, supervised, and controlled by the federal and state ministry of education and local education authority in the case of local government. The Federal Ministry of Education is shouldered with responsibility for the total policy formulation and certifying quality administration of education, though, the federal government is involved with higher institutions. Secondary education is mostly the responsibility of the state government and elementary education is largely the responsibility of local government. Nigeria's system of education is based on the (6-3-3-4) system, six years in primary school and three years in junior secondary, these six and nine years combine to make what is known as basic education in the country. The remaining (34), three years is for senior secondary and a minimum of four years in higher institutions. The country has adopted this system since 1989 [2].

E-teaching and E-learning conducted via the internet have been in existence for about two decades. E-learning can be viewed as the online delivery of instructions. It is also defined as the assimilating of learning with technology (Okah, 2009; Okah, 2010). It is instruction delivered through purely digital technologies such as CD ROM, the internet, and private networks (Landon and Landon, 2010). E-learning can also be defined as the online delivery of information for education, training, or knowledge management (Turban et al, 2010) or performance management (Okah et al, 2011). Governments globally play an important role in funding, developing, and regulating information and communication technology (ICT) infrastructure as well as promoting internet accessibility. It can be presumed that ICTs are important for the present-day educational development of any country [3]. E-teaching and E-learning encompass the use of an electronic method that is relatively related to internet-based teaching and learning in general. Tracy (1995) defines the term internet as the international network of communication in which computers in the Wide Area Network (WAN) talk to each other.

(Manir K. 2009) Studied the problems, challenges, and benefits of implementing e-learning in Nigerian universities [4]. Jumoke S. et al reported that various studies indicate that there is a positive relationship between using information and communication technology (ICT) in colleges and students' academic performance in many courses. Students are more comfortable and satisfied in an ICT classroom and using this as a benchmark, alongside the traditional classroom learning will go a long way to faster learning thereby increasing the academic achievement of the students remarkably. [5] (Sabina N. 2012) also studied the Challenges in the applications of e-learning by secondary school teachers in Anambra State, Nigeria. Challenges in the applications of elearning by secondary school teachers in Anambra State, Nigeria. The research reported an inadequate ICT facility and lack of technical know-how from the part of teachers as the bottleneck in the application of e-learning in the study area [6]. Sunday C. et al. 2018 examines the utilization and adoption of e-learning tools by lecturers in Nigerian privately-owned tertiary institutions [7]. Mohammed A. et al. explore the critical factors and challenges bedeviling the E-learning system during the pandemic [8]. Elearning satisfaction levels were described to be better in developed countries compared to developing countries. However, Maria $\mathrm{S}$ et al. report that the majority of participants in their study agreed that E-learning was a satisfactory tool in acquiring knowledge [9]. 
Nigeria's system of education is transforming for the better and it is moving drastically. The rate of increase in demand for online education is felt generally these days with easing speed improvement and development in the realm of information and communication technology. The great update is numerous E-learning providers are discovering huge projections across the nation. As a consequence, of this, more E-learning solution providers are showing up with vast ideas of exploring the information and communication technology hub to promote universal competitiveness. However, the country is confronted with challenges of infrastructural facilities, the search engine optimization (SEO) of Learning Nuggets Company advised the Nigerian government to assimilate technology into its education sector. Hence, it is anticipated that Nigeria is going to record many successes soon [10].

\section{OBJECTIVES OF THE STUDY}

The objectives of this study are to show how E-learning can be of great importance in transforming Nigeria's current system of education especially in times of uncertainties like the recent outbreak of COVID-19, which leads to the closure and short down of all schools in the entire country.

\section{SCOPE AND LIMITATION OF THE STUDY}

The study is limited to only Nigeria's system of education. About 200 responses were analyzed for the study. Below is the map depicting Nigeria and its thirty-six states and capital territory Abuja.

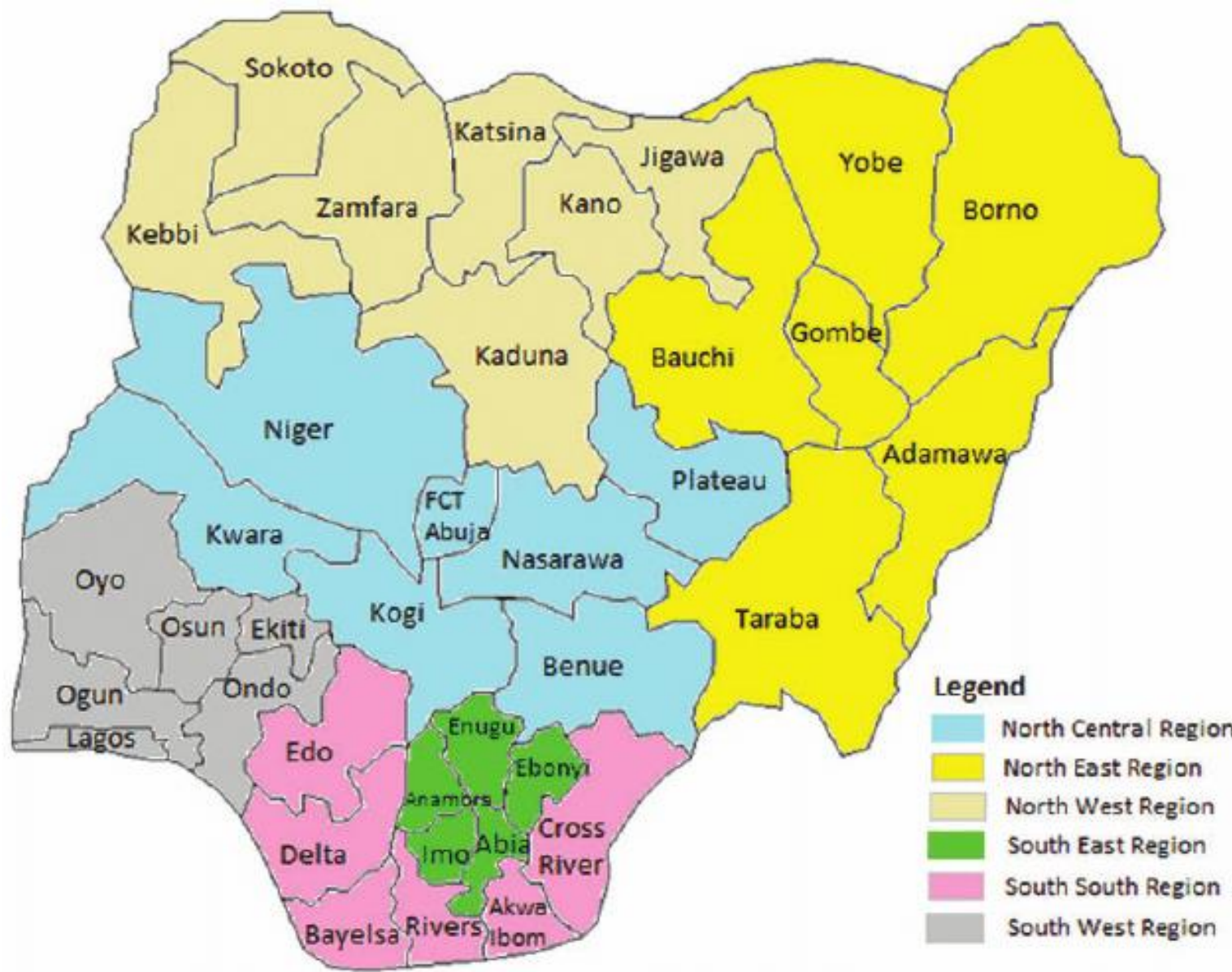

\section{METHOD}

A quantitative survey was conducted and the descriptive statistics method of data analysis was used to measured and assessed the satisfaction and perception of Nigerian students regarding E-learning during Emergency, pandemic, and uncertainty. A wellstructured questionnaire was composed of discussions with other scholars.

The data were collected through the questionnaire method of data collection. Google form was used to generate questions and a link was and shared in different social media handles (Facebook, WhatsApp, and Telegram). Our study adopted a descriptive statistical analysis of frequencies of response to each study question. More than two hundred responses were recorded and analyzed using pie charts and bar charts. The objectives of the study were included in the questionnaire and all participants agreed to a consent statement for voluntary participation and declarations of confidentiality and anonymity before answering the questions. Information regarding student's experience and their perceptions of E-learning was also generated. The questions measured, commonly used online platform used for E-learning in the pandemic, emergency, and period of uncertainty. 


\section{RESULTS AND DISCUSSIONS}

E-learning is a prevailing method of academic undertakings among students during a pandemic and other unfortunate situations that may not allow the normal offline classes. It has become very crucial to measure the satisfaction and perception among Nigerian students to identify the problems and challenges from the student's views and the possible solutions to those problems. Consequently, the present work aimed to measure the satisfaction and perception among students towards E-learning during the pandemic.

The results of our study were analyzed using Microsoft excel. The output of our findings was depicted both in simple descriptive statistical pie charts and bar charts.

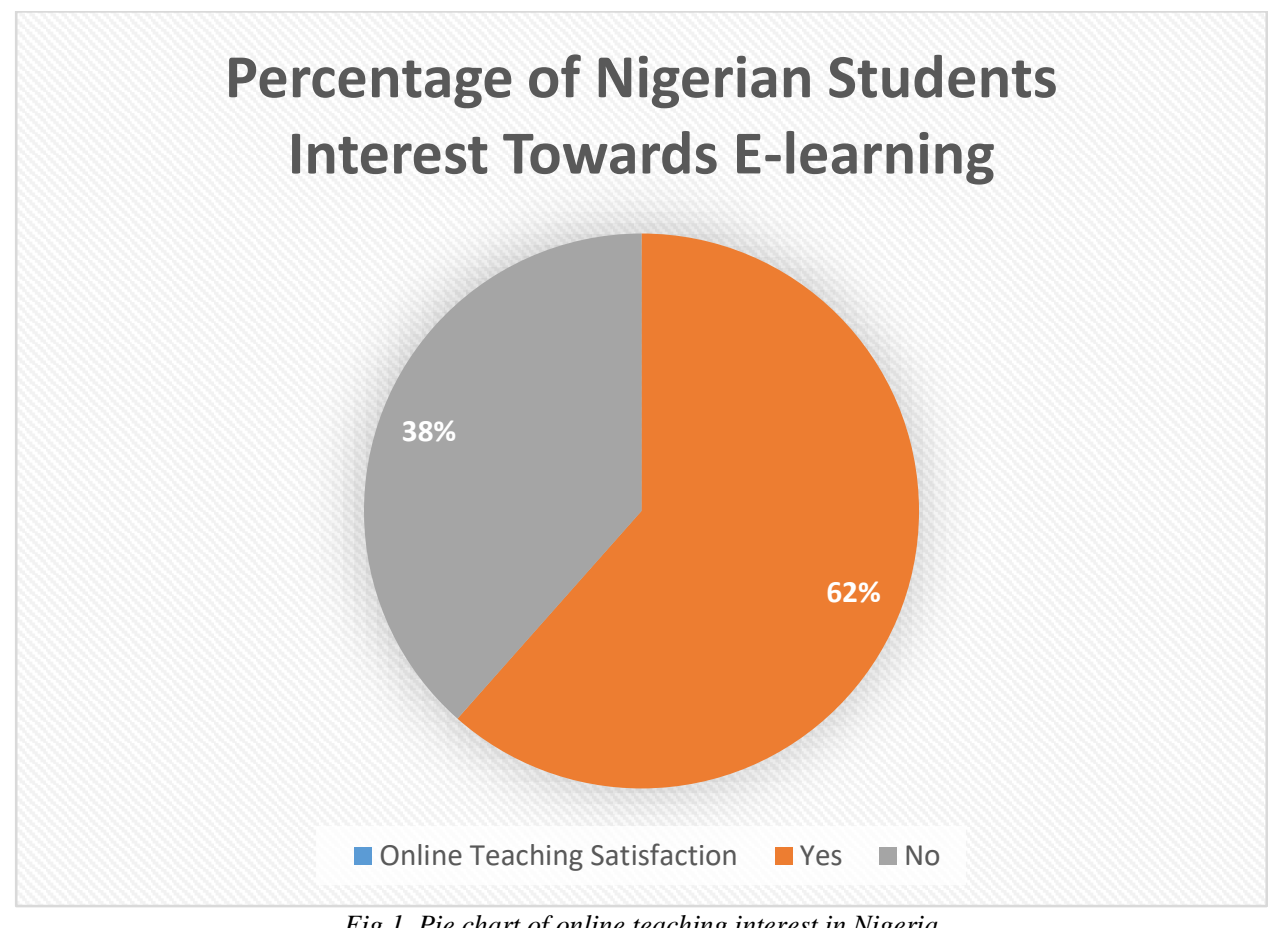

Figure 1 shows the percentage of Nigerian students based on their interest in the E-learning system of education. As it can be seeing clearly in the figure, about $62 \%$ have expressed their interest in the E-learning system while the remaining $38 \%$ out of about 200 hundred respondents have expressed their dissatisfaction with the system.

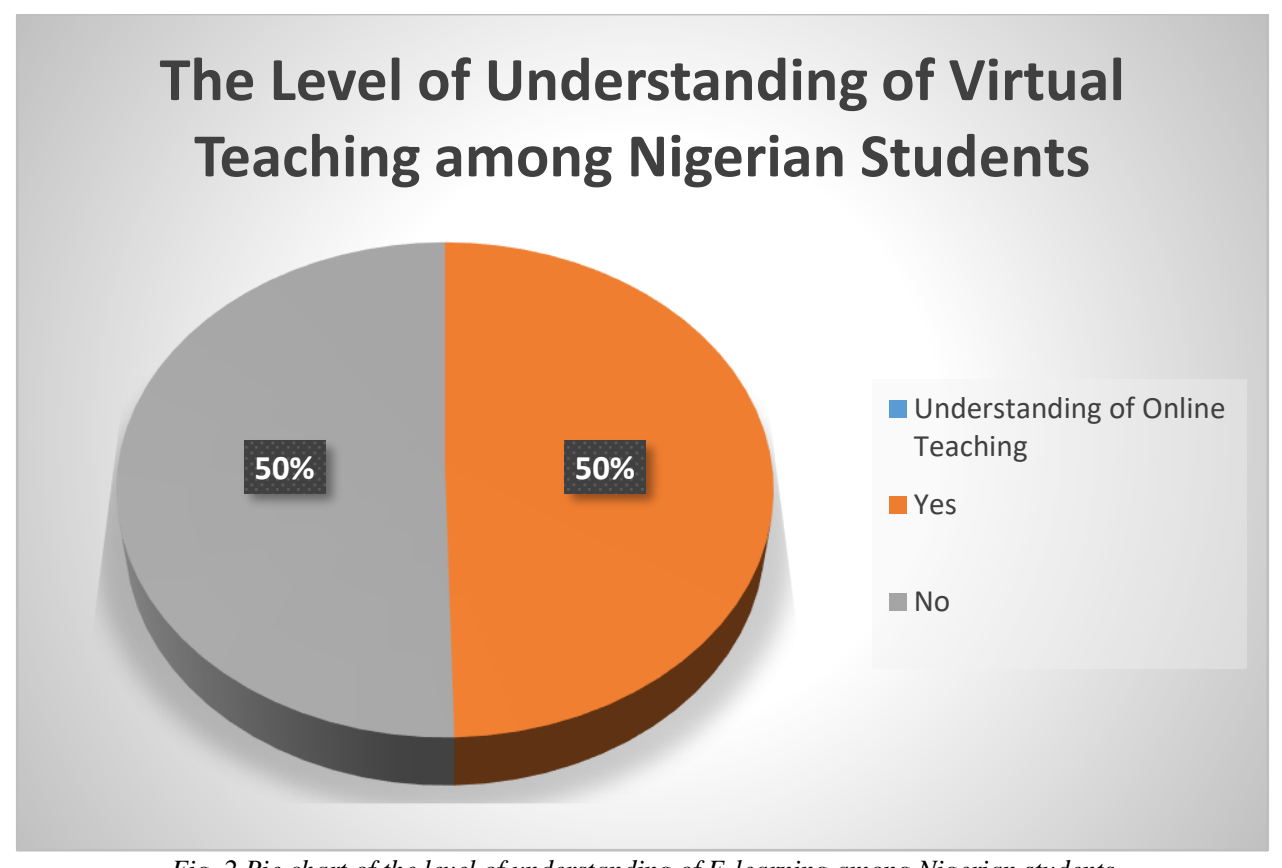

Fig. 2 Pie chart of the level of understanding of E-learning among Nigerian students 
Figure 2 depicted the percentage level of E-learning from about two hundred respondents. The percentage shows that the understanding level of virtual learning is almost similar to that of the current traditional system of education practice in Nigeria.

\section{Nigerian Students Perceptions Towards E-learning}

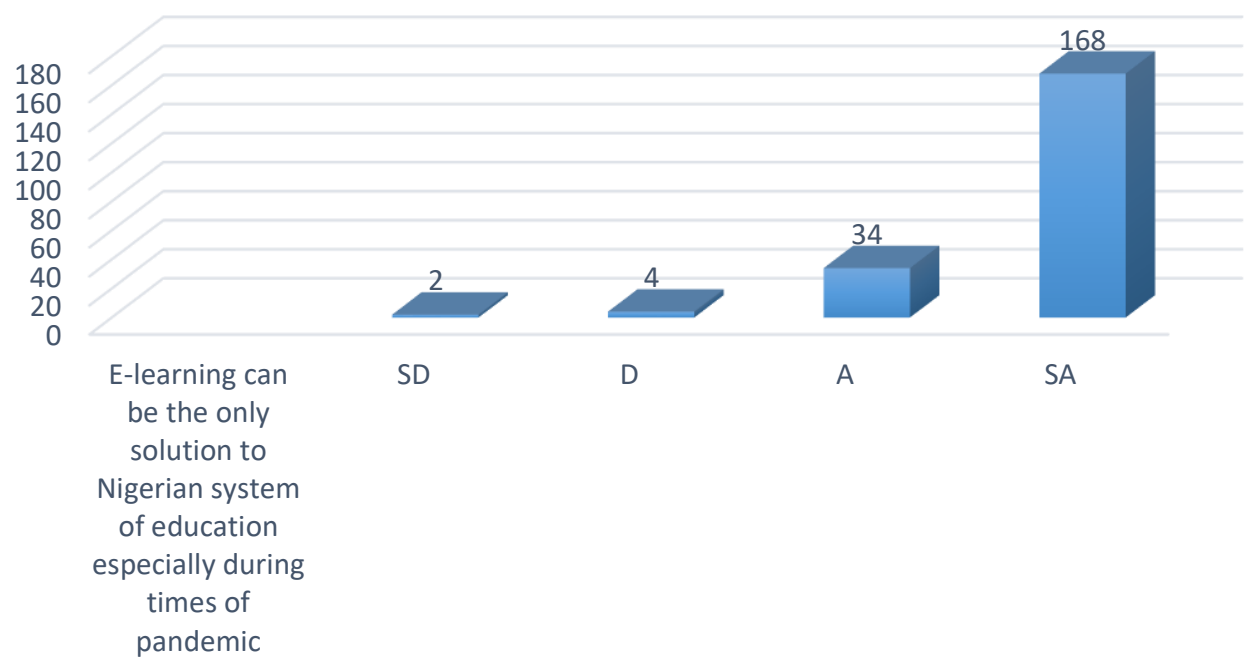

Fig. 3 a bar chart for the perceptions of Nigerian students on E-learning.

Figure 3. Shows the views of our respondents on the use of E-learning especially during a pandemic. One hundred and sixty-eight responses were recorded to strongly agree while thirty-four responses were recorded to have agreed that E-learning is the best and only solution to Nigeria's education system during a hard and uncertain time of the pandemic. While four and two responses disagreed and strongly disagreed respectively.

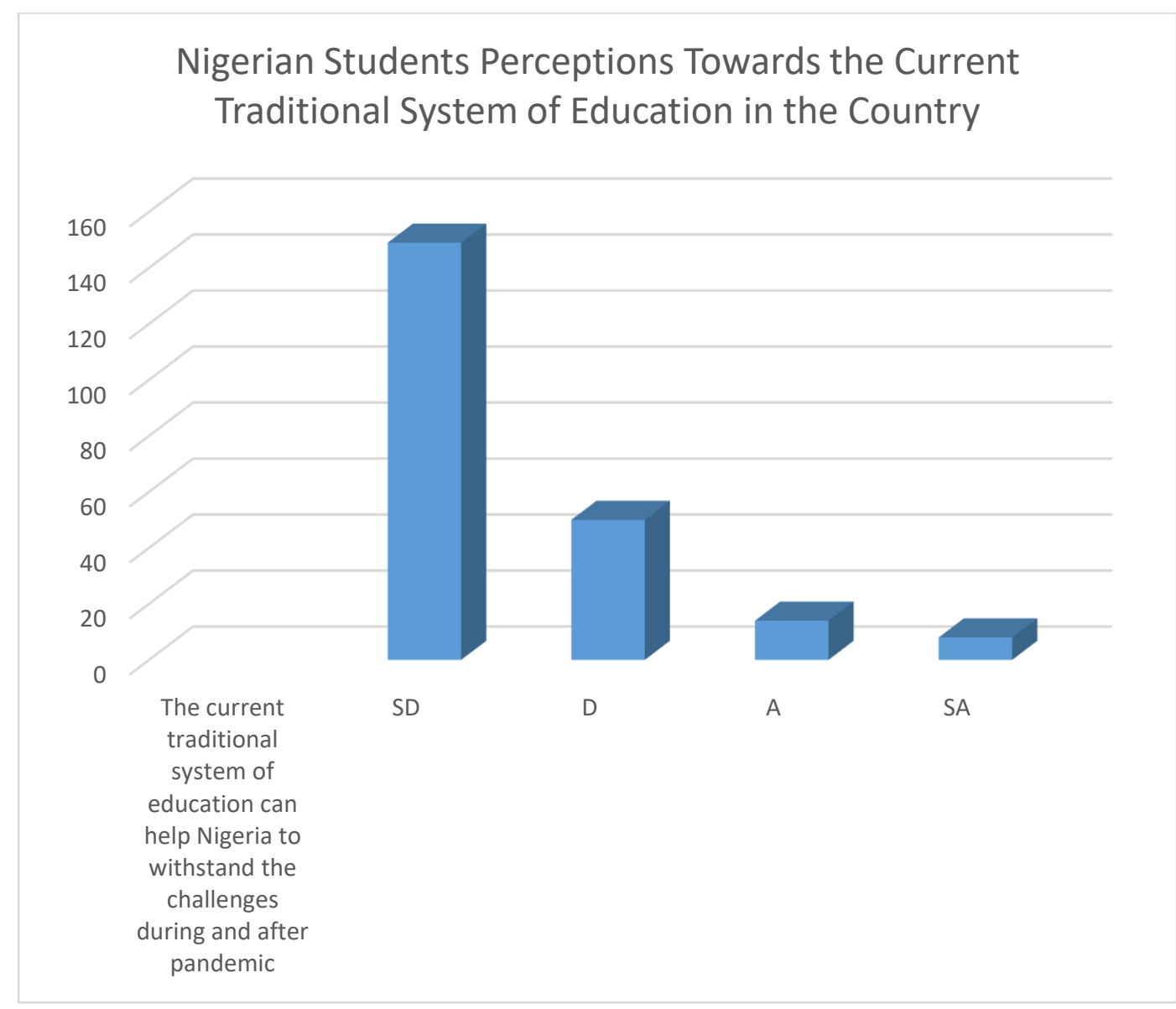

Fig. 4 Perceptions of students on the country's current system of education 
Figure 4 above displayed the opinions of the respondents on the current system of Nigeria's education. One hundred and forty nine (149) as well as fifty (50) responses were reported to strongly disagree and disagree respectively the current traditional system will not assist the country in managing and sustainability of its educational system in times like this. While fourteen (14) and eight (8) responses were recorded to have agreed and strongly agree that, the current traditional system of the country's education can help Nigeria to withstand the challenges during and after situations of the pandemic.

\section{CONCLUSION}

Our findings show that many students prepare E-learning than the current traditional model of teaching in the study area. This can be attributed to so many factors like, the effort to compete with their counterparts in developing countries globally. The rising acceptability of electronic learning may also be attributed to its ability to enable students to study without the barrier of space and time and at their conveniences. The level of students' understanding using E-learning mode to the current system of education, is the same based on our findings. Though despite the preference of E-learning than the current educational system indicates by our findings, the country is facing many challenges such as lack of stable power supply, non-provision of information and communication technology (ICT) in teachers training programs, internet connectivity is unpredictable and slow due to narrow bandwidth and limited expertise to mention but few. The agency in charge of information and communication technology needs to double its efforts in regulating the activities of internet service providers in the country to help its citizen students in getting access to E-learning easy and at an affordable cost.

Similarly, our findings also confirmed that many Nigerian students who are studying in different learning institutions in the country believed E-learning mode is the solution to the dwindling situation of education especially during the trial and uncertain times like the recent outbreak of coronavirus which results in total closure of schools and other similar cases. Nevertheless, so many factors may be associated with their decisions in choosing the E-learning mode such as redundancy which the current situation cause, and their inability to get more clarification on their courses from teachers which E-learning can supplement in a matter of some minutes.

This finding can be of great importance to the Nigerian government, federal and state ministries of education, policymakers, private school owners, and other stakeholders in the educational sector in the country. The study can also be of paramount significance to other developing countries like Nigeria.

\section{REFERENCES}

[1] https://www.worldometers.info/world-population/nigeria-population/

[2] https://theconversation.com/education-in-nigeria-is-in-a-mess-from-top-to-bottom-five-things-can-fix-it

[3] https://lifelearners.ng/challenges-of-e-learning-in-nigeria/ 10:31pm 14-06-2020

[4] Manir K. Problems, Challenges, and Benefits of Implementing E-learning in Nigerian Universities: An Empirical Study. International Journal of Emerging Technologies in Learning (iJET) 4 (1), 66-69, 2009. 3:00 pm 15/08/2020.

[5] Soyemi, Jumoke and Ogunyinka, O.I and Soyemi, Olugbenga Babajide (2012) Integrating Self-Paced E-Learning with Conventional Classroom Learning in Nigeria Educational System. Journal Plus Education, 2012 (1). pp. 195-203. ISSN 2068 - 1151

[6] https://studyinnigeria.wordpress.com/tag/e-learning-in-nigeria/

[7] businessdayonline.com/2013/04/e-learning-solutions-provider-sees-huge-prospect-in-nigeria/

[8] Sunday C. E, Vera C. C, Adenike O. B. Utilization and Adoption of e-learning facilities by lecturers in Nigerian private tertiary institutions. International Journal of Educational Technology in Higher Education 15 (1), 34, 2018).

[9] Maria, S. A.; Naseer, A.; Batool, S.; Abdullah, A.; Sumera, S.; Shaur, S.; Rana, S. A.; Fahim, V.; Tariq, A. E-learning for Health Sciences Amids the COVID-19 Pandemic. IOS Press. 67, 3, 549-556, 2020

[10] Mohammed A. A, Ahmad A, Ahmad A. Exploring the critical challenges and factors influencing the E-learning system usage during COVID-19 pandemic. Springer Science+Business Media, LLC, part of Springer Nature 2020. 